\title{
ON THE INTERMEDIATE POINT IN CAUCHY'S MEAN-VALUE THEOREM
}

\author{
DOREL I. DUCA AND OVIDIU POP
}

Abstract. If the functions $f, g: I \rightarrow \mathbb{R}$ are differentiable on the interval $I \subseteq \mathbb{R}$, then for each $x, a \in I$ there exists a real number $\theta \in] 0,1[$ such that

$$
(f(x)-f(a)) g^{(1)}(a+\theta(x-a))=(g(x)-g(a)) f^{(1)}(a+\theta(x-a)) .
$$

In this paper we study the behaviour of the number $\theta \in] 0,1[$, when $x$ approaches $a$.

Mathematics subject classification (2000): 26A24.

Key words and phrases: Cauchy's theorem, intermediate point, mean-value theorem.

\section{REFERENCES}

[1] Herbert Amann, JoAchim Escher, Analysis, Birkhauser Verlag, Basel-Boston-Berlin, I (1998), II (1999), III (2001).

[2] D. ANDRICA, D. I. DuCA, I. PuRdEA AND I. Pop, Basic Mathematics (in Romanian), Studium Publishing House, Cluj-Napoca, 2002.

[3] D. Azagra, J. Gomez and J. A. Jaramillo, Rolle's Theorem and Negligibility of Points in Infinite Dimensional Banach Spaces, Journal of Mathematical Analysis and Applications, 213 (1997), 487-495.

[4] R. G. BARTLE, D. R. SHERBERT, Introduction to Real Analysis, 3rd., J. Wiley, New York, 2000.

[5] D. I. DuCA, A Note on the Mean Value Theorem, Didactica Matematicii, 19 (2003), 91-102.

[6] D. I. DucA, O. Pop, On the Intermediate Point in the Mean Value Theorem, to appear

[7] G. B. Folland, Real Analysis, J. Wiley, New York, 1999.

[8] M. FurI, M. MARTELl, On the Mean Value Theorem, Inequality, and Inclusion, The American Mathematical Monthly, 98, (1991), 840-846.

[9] Elliott H. Lieb, Michael Loss, Analysis, American Mathematical Society, 1997.

[10] R. MERA, On the Determination of the Intermediate Point in Taylor's Theorem, The American Mathematical Monthly, 99, (1992), 56-58.

[11] J. P. PENOT, Mean-Value Theorem with Small Subdifferentials, Journal of Optimization Theory and Applications, 94, (1997), 209-221.

[12] W. Rudin, Real and Complex Analysis, third edition, McGraw Hill, New York, 1987.

[13] E. SCHECHTER, Handbook of Analysis and its Foundations, Academic Press, San Diego, 1997. 